\title{
The Animal in Epistemology: Wittgenstein's Enactivist Solution to the Problem of Regress
}

\author{
Danièle Moyal-Sharrock \\ University of Hertfordshire \\ d.moyal-sharrock@herts.ac.uk
}

\begin{abstract}
In this paper I briefly summarize the nature of Wittgenstein's 'hinge certainties', showing how they radically differ from traditional basic beliefs in their being nonepistemic, grammatical, nonpropositional and enacted. I claim that it is these very features that enable hinge certainties to put a logical stop to justification, and thereby solve the regress problem of basic beliefs. This is a ground-breaking achievement - worthy of calling On Certainty Wittgenstein's 'third masterpiece'. As I go along, I question some differing interpretations and respond to some objections from fellow-readers of On Certainty: Duncan Pritchard, Michael Williams and Crispin Wright.
\end{abstract}

Keywords: Wittgenstein, On Certainty, epistemology, regress problem, basic beliefs, hinge certainty, knowledge, Enactivism.

$* * * * * * * * *$

The first, and only time, I heard Crispin Wright speak on On Certainty was at Kirchberg in 2003. At the Q\&A session, I asked him: 'What have you done with the animal in On Certainty'? And his reply was: 'There is no animal in epistemology'. Well, Wright might want to keep the animal out of epistemology, but Wittgenstein certainly didn't, and I think he was right:

I want to conceive [this certainty] as something that lies beyond being justified or unjustified; as it were, as something animal. (OC 359)

Wittgenstein's revolutionary insight in On Certainty is that what philosophers have traditionally called 'basic beliefs' - those beliefs that all knowledge must ultimately be based on - cannot, on pain of infinite regress, themselves be propositional beliefs. They are really animal or unreflective ways of acting which, once formulated (e.g. by philosophers), look like propositional beliefs. It is this misleading appearance that leads philosophers to believe that at the foundation of thought is yet more thought. For, though they often resemble empirical conclusions, basic certainties (or 'hinge certainties' or 'hinges' - as I shall also call them following Wittgenstein's hinge metaphor [OC 341]) constitute the ungrounded, nonpropositional underpinning of knowledge, not its object. In thus situating the foundation of knowledge in nonreflective certainties that manifest themselves as ways of acting, Wittgenstein has found the place where justification comes to an end, and solved the regress problem of basic beliefs - and, in passing, shown the logical impossibility of radical or global scepticism. I believe that this is a groundbreaking achievement for philosophy - worthy of calling On Certainty Wittgenstein's 'third masterpiece'. In this paper, I briefly flesh out the 
account of On Certainty that I have just summarized while considering some objections and differing interpretations from fellow-readers of On Certainty.

\section{Certainty versus knowledge}

Wittgenstein's last notes were posthumously entitled On Certainty. They constitute his attempt, prompted by G. E. Moore's 'Proof of an External World', to understand the nature of our basic assurance - our assurance about such things as 'Human beings are born and die', 'The earth has existed long before I was born', 'I am standing here', 'I have a body', 'Here is a hand'. Wittgenstein agrees that the objects of Moore's assurance are those of our most unquestionable beliefs, but disagrees that the certainty in question is of an epistemic nature; he believes this assurance to be of a more foundational breed than knowing:

When I say 'how do I know?' I do not mean that I have the least doubt of it. What we have here is a foundation for all my action. But it seems to me that it is wrongly expressed by the words 'I know'. (OC 414)

Wittgenstein does not take this certainty to be a knowing because he adheres to the standard view of knowledge as justified true belief: 'One says 'I know' when one is ready to give compelling grounds. 'I know' relates to a possibility of demonstrating the truth' (OC 243); 'Whether I know something depends on whether the evidence backs me up or contradicts me' (OC 504; see also OC 91). Basic certainty, as he sees it, has no truck with truth or justification: 'If the true is what is grounded, then the ground is not true, nor yet false' (OC 205). To say that basic certainties are indubitable is not to say that they have been proved true beyond doubt, but stems from their not being susceptible of confirmation or falsification at all; from their being logically impervious to doubt. At some point, justification and doubt lose their sense; there where the spade turns is the ungrounded ground, where 'justification comes to an end' (OC 192).

\section{Conceptual, not contextual}

Our basic certainties are ungrounded; we do not hold them because we have compelling grounds for them (OC 243); nor are they objects of subjective or psychological conviction, but of logical conviction (OC 494). That is, doubting them would be tantamount to having lost the bounds of sense: 'If someone said to me that he doubted whether he had a body I should take him to be a half-wit' (OC 257); 'I cannot doubt this proposition without giving up all judgment' (OC 494); 'There are cases where doubt is unreasonable, but others where it seems logically impossible' (OC 454)

Nor is it possible to be mistaken about a hinge certainty: if I believe that I am sitting in my room when I am not or that my biological parents are lions, it isn't my possibly being mistaken that would be under investigation, but my knowledge of English or, more sadly, my sanity. A mistake results from negligence, fatigue or ignorance; we cannot say of someone who believes that she was never born that she is 'mistaken': 
In certain circumstances a man cannot make a mistake. ... If Moore were to pronounce the opposite of those propositions which he declares certain, we should not just not share his opinion: we should regard him as demented. (OC 155)

In thus logically closing the door to doubt and mistake as regards our basic certainties, Wittgenstein closes the door to the contextualism Michael Williams attributes to him (1991, 26). For Wittgenstein, it isn't, as Williams suggests, that the justificatory process need not actually occur (though grounds must be produced on demand), or that it need not be selfconscious (2001, 35), but that basic certainty is conceptually groundless, groundless by nature: 'I want to conceive it as something that lies beyond being justified or unjustified' (OC 359). If our certainty stems, or could stem, from justification, it is not a hinge certainty (OC 94).

On Williams' neo-Humean reading, Wittgenstein believes sceptical doubt to have no bearing in the pragmatic air of ordinary life, but to be legitimate and serious in the context of philosophical reflection. However, as we've just seen, there can be for Wittgenstein no context in which our hinge certainties can be doubted or justified, for their indubitability is conceptual, not contextual. It isn't a hinge that can be doubted in some contexts and not in others; but a hinge can never be doubted whereas the doppelgänger of a hinge (that is, a twin sentence which expresses an empirical or an epistemic proposition) can be, and this misleads us into thinking that the hinge itself can, in some contexts, be doubted". 'The world has existed for more than five minutes': this sentence may well constitute a falsifiable or empirical proposition in a sci-fi movie, but it cannot be a falsifiable proposition, and therefore (on Wittgenstein's view) a proposition tout court, for a human being in any context ${ }^{2}$. For Wittgenstein, the Cartesian demon is never a plausible threat; he has no more grip in the philosophical study than he does in our ordinary life.

What may give the impression of contextualism is the difference Wittgenstein marks in On Certainty between the use of 'I know...' in ordinary life and its use in philosophical discourse:

\footnotetext{
${ }^{1}$ Note that the notion of doppelgänger helps us to consider the use of identical sentences in different contexts without any sense or meaning being intrinsically attached to these sentences. As Pritchard rightly notes: '... there is nothing in Wittgenstein's argument ... which licenses the kind of contextualism that Williams proposes' (2011a, 16).

${ }^{2}$ So it isn't that the same proposition becomes unfalsifiable in one context; but that qua hinge the sentence does not express a proposition at all (it expresses, as we shall see, a rule of grammar or rule of a language-game (OC 95) or bound of sense). The same goes for personal hinges (for a taxonomy of hinges listing them as linguistic, personal, local and universal, see Moyal-Sharrock (2007)): my speaking French is a personal hinge, a certainty which is for me neither falsifiable nor verifiable; the fact that someone may say of me that I speak French (because they've heard me speak it) and that this is a falsifiable proposition for them (I could have been aping a French speaker) does not make it a falsifiable proposition for me. Or again, what is for me a hinge certainty (e.g., 'I am in this room') can constitute a verifiable fact for someone else (e.g., who is not in this room or who is blind), but this does not make my hinge certainty into a verifiable empirical proposition. There is a first-third person asymmetry here that we must be wary of. Relatedly, to take hinge certainties to be unfalsifiable empirical propositions (Hacker (1996, 217); see also Glock in this issue), or judgments that have a normative role (Coliva, 2010, 80; and in this issue) is, I suggest, to attribute to hinges uses that belong to their Doppelgänger. Moreover, the idea of unfalsifiable empirical propositions, at best, takes us back to the notion of 'necessary propositions' that Wittgenstein took great pain to reform (see, e.g. MWL 61-65).
} 
What I am aiming at is also found in the difference between the casual observation 'I know that that's a...', as it might be used in ordinary life, and the same utterance when a philosopher makes it. (OC 406)

But Wittgenstein suggests we treat these knowledge claims differently not because he thinks we know our basic certainties in ordinary life and not in the philosopher's study, but because Moore's being a philosopher ought to constrain him to use 'I know...' with technical precision - that is, exclusively in cases of justified true belief - whereas this cannot be demanded of the ordinary person: we cannot and should not expect her to use 'I know...' only when it is 'justified true belief' she means by it. Wittgenstein refuses to admonish or correct our ordinary use of language, but the philosopher must be made accountable:

For when Moore says 'I know that that's a...' I want to reply 'you don't know anything!' - and yet I would not say that to anyone who was speaking without philosophical intention. (OC 407; original emphasis)

So that, for Wittgenstein, we are entitled to say: 'I know...' in ordinary life where a philosopher in the study is not thus entitled, but this does not imply that we $d o$ in fact know in ordinary life.

It isn't, as Williams claims, that sceptical doubts are unnatural doubts (1991, 2), and therefore sustainable only in the artificial or unnatural conditions of philosophical reflexion, but that they are not doubts at all. In On Certainty, Wittgenstein elucidates the concept of doubt in two important ways: he shows that universal doubt is impossible and that not everything that has the appearance of doubt is doubt:

If someone said that he doubted the existence of his hands, kept looking at them from all sides, tried to make sure it wasn't 'all done by mirrors', etc., we should not be sure whether we ought to call that doubting. We might describe his way of behaving as like the behaviour of doubt, but his game would not be ours. (OC 255)

In some cases, what looks like doubt is only doubt-behaviour. Of course, where doubt has no rational motivation or justification, it may have (pathological) causes (OC 74), but normal doubt must have reasons. It isn't enough to say or imagine we doubt: genuine doubt, like suspicion, must have grounds (OC 322, 458). If Williams thinks sceptical doubt possible, it may be because - like Hume, Moore and most philosophers since Descartes - he takes the mere articulation of doubt for doubt.

Wittgenstein's recognition that the sceptic's doubt is only doubt-behaviour is spurred by his realization that it is hinged on the very certainties it dismisses. For, were she not hinged on some certainties, the sceptic could not even formulate her doubt:

If I wanted to doubt whether or not this was my hand, how could I avoid doubting whether the word 'hand' has any meaning? So that is something I seem to know after all. (OC 369) ['know' is in italics]

But more correctly: The fact that I use the word 'hand' and all the other words in my sentence without a second thought, indeed that I should stand before the abyss if I wanted so much as to try doubting their meanings - shews that absence 
of doubt belongs to the essence of the language-game, that the question 'How do I

know...' drags out the language-game, or else does away with it. (OC 370)

The possibility of meaningful thought (language) demands certainty: this means that the sceptic's scepticism depends on certainty for its very conception or formulation. At 'the foundation of all operating with thoughts (with language)' (OC 401) is an essential certainty, a certainty endorsed every time a doubt (towards it) is formulated. Its being essential to our making sense means that this certainty underpins all our questions and doubts (OC 341), including the sceptic's universal doubt, thereby invalidating it. It seems to me that what we have here is a knock-down objection to universal scepticism.

Although Hume may be seen to have progressed from Descartes when he admits that sceptical doubt is not sustainable in ordinary life, it takes Wittgenstein to recognize that universal doubt is not sustainable at all, inside the study or out - and this, not for pragmatic but for conceptual reasons: 'A doubt that doubted everything would not be a doubt' (OC 450); 'If you tried to doubt everything you would not get as far as doubting anything. The game of doubting itself presupposes certainty' (OC 115). Wittgenstein demystifies sceptical doubt; he shows that the sceptic - and any philosopher who, in the study, takes universal doubt seriously - are only under, what he calls, an illusion of doubt (OC 19).

In On Certainty, then, Wittgenstein takes Moore to task for confusing knowledge with the nonepistemic brand of conviction that logically underlies it, and he drives a categorial wedge between them: '"Knowledge" and "certainty" belong to different categories' (OC 308). In doing this, he breaks with the traditional presupposition in epistemology that we know our basic beliefs. But in spite of Wittgenstein's categorial distinction, some commentators insist on seeing the certainty which underpins knowledge as itself a knowing. As Williams puts it: 'Knowledge ... emerges out of prior knowledge' (2001, 176), which makes our 'bedrock certainties' unavoidably propositional for, he asks, how could our basic beliefs not be propositional if they are to generate our nonbasic beliefs (ibid., 97) ${ }^{3}$ ?

Yet the clear message of On Certainty is precisely that knowledge does not have to be at the basis of knowledge. For Wittgenstein, underpinning knowledge are not default justified propositions that must be susceptible of justification on demand but nonpropositional certainties - certainties 'in action' or ways of acting - that can be verbally rendered for heuristic purposes and whose conceptual analysis uncovers their function as unjustifiable rules of grammar. So that basic certainties stand to nonbasic beliefs, not as propositional beliefs stand to other propositional beliefs, but as rules of grammar stand to propositional beliefs ${ }^{4}$. Hence the absence of propositionality as regards them. Knowledge need not emerge

\footnotetext{
3 Williams: 'However basic knowledge is understood, it must be capable of standing in logical relations to whatever judgements rest on it. For example, it must be capable of being consistent or inconsistent with them. But this means that even basic knowledge must involve propositional content' $(2001,97)$.

${ }^{4}$ This is the logical relationship between hinges and non-hinge propositions that Williams demands: that between rules and propositions. For most epistemologists, to ask for the ground of a belief is to ask for yet another belief, for only beliefs (and other intentional states) can stand in logical relation to other beliefs. But this is to overlook the fact that grammatical rules can stand in logical relation to beliefs - as indeed they must: as the necessary enablers of sense. I cannot come to the belief that 'It is indeed a hand I see on this blurry photograph' unless I am 'hinged' on the grammatical rule that 'This 1 is what we call "a hand"'. In the same way that I cannot investigate the age of the earth unless I am 'hinged' on such grammatical rules as 'The earth exists'; 'The earth has existed for a long time'; 'We have a concept of time, and it includes measurement of age in years' etc.
} 
from knowledge: 'For why should the language-game rest on some kind of knowledge?' (OC 477).

\section{An animal and grammatical certainty}

Our basic certainty is not rational but arational, animal: 'I want to conceive it as something that lies beyond being justified or unjustified; as it were, as something animal' (OC 359). This isn't to say that some of our certainties cannot be third-person verified or justified, but that we (first-personally) do not hold or arrive at a certainty by following a line of thought ${ }^{5}$; 'it is anchored in all my questions and answers, so anchored that I cannot touch it' (OC 103). Something so anchored that we cannot touch it - in fact, something that 'belong[s] to the scaffolding of our thoughts' - is therefore not just in no need of justification; it is, as we saw, not susceptible of justification at all. Upon reaching 'rock bottom' (OC 261), we are no longer dealing with propositions that can be justified or falsified, but with the scaffolding of thought; that is, with grammar - grammar, in Wittgenstein's sense, being the reality-soaked conditions or rules that govern the use of our words ${ }^{6}$. Wittgenstein realizes that Moore-type propositions, though they have the form of empirical propositions, are in fact expressions of rules of grammar:

When Moore says he knows such and such, he is really enumerating a lot of empirical propositions which we affirm without special testing; propositions, that is, which have a peculiar logical role in the system of our empirical propositions. (OC 136)

That is, a grammatical role. As Crispin Wright puts it: 'the unwavering - dogmatic confidence we repose in these propositions ... attaches to them in their role as in effect rules' (2004a, 35-36). But what Wright does not see is that inasmuch as hinge certainties are rules, they cannot be propositions.

On Wittgenstein's bipolar view of the proposition, for a sentence to be a proposition, it must be susceptible of truth and falsity. However, bivalence suffices for my argument here. Inasmuch as hinges are neither true nor false - 'the ground is not true nor yet false' (OC 205),

However, if the epistemologist insists on having other beliefs at the ground, let them be nonpropositional beliefs, such as beliefs-in (I flesh this out in Moyal-Sharrock 2007, Ch. 9).

${ }^{5}$ We mistakenly think we come to the basic certainty that 'Human beings need nourishment' or 'Babies do not kill' in the same way we come to a conclusion from reasoning. This confusion is due to our assuming that some reasoning must always take place for certainty to occur: 'Normal thought envelops even our basic judgments with a rhetoric of reasons' cautions Crispin Wright (2007a, 140) - though he seems, I will suggest, not to have sufficiently heeded that warning. Wittgenstein makes clear that although we invariably invoke an implicit or ghostly reasoning to explain our most basic beliefs, in fact no such reasoning takes place; we do not arrive 'at the conviction by following a particular line of thought' (OC 103).

${ }^{6}$ By 'reality-soaked' (I owe this expression to Bernard Harrison), I mean embedded - as opposed to grounded in or justified by - reality. Wittgenstein has what I call a 'thick' as well as a 'thin' conception of rules. Examples of thin grammatical rules are: ' $2+2=4$ '; 'This is (what we call) a table'; thick grammatical rules are 'reality-soaked'; rules that are conditioned by 'very general facts of nature'; e.g., that human beings are born and die; that infants cannot take care of themselves etc. 'The rule we lay down is the one most strongly suggested by the facts of experience' (AWL 84; my emphasis). This does not make thick rules into empirical propositions for thick rules are not inferred from reality, but conditioned by it (see OC 617). No epistemic process (justification, inference, conclusion etc.) occurs; and no correspondentist view: rules of grammar are embedded in, not derived from, or true to, reality. See note 16 below. 
they cannot be propositions. As Wittgenstein writes: 'the end is not certain propositions' striking us immediately as true' (OC 204). So why does he, in other passages, refer to our basic beliefs as 'propositions'? The inconsistency is partly justified by the fact that the nonpropositionality of hinges only progressively makes itself clear to him. It should also be recognized that, of all the insights Wittgenstein comes to in On Certainty, the nonpropositionality of basic beliefs is the most ground-breaking, and must therefore have been the most difficult to achieve and process; he does, however, achieve it:

Giving grounds, however, justifying the evidence, comes to an end; - but the end is not certain propositions striking us immediately as true, i.e. it is not a kind of seeing on our part; it is our acting, which lies at the bottom of the languagegame. (OC 204)

The nonpropositional nature of basic certainties is one with their being ways of 'acting' and to their being 'animal'. Whether a hinge certainty starts out as instinctive or natural (e.g., our certainty of having a body) or is second-nature; i.e. the result of conditioning (e.g., our certainty that 'This is (what we call) a table'), it is best described as a reflex action:

It is just like directly taking hold of something, as I take hold of my towel without having doubts. (OC 510).

And yet this direct taking-hold corresponds to a sureness, not to a knowing. (OC 511)

With such repeated references to hinges as reflex-like ways of acting and not propositions striking us immediately as true, Wittgenstein puts paid to the picture of basic beliefs as propositional beliefs that lie dormant in some belief box tacitly informing our more sophisticated thoughts. On his view, the hinge certainty verbalised as: 'I have a body' is a disposition of a living creature which manifests itself in her acting in the certainty of having a body ${ }^{7}$. Certainty is a way of acting, not a tacit belief.

But how can ways of acting, albeit basic (i.e. either instinctive or second-naturally animal) also be rules of grammar? ${ }^{8}$ This dual aspect of hinges simply reflects the philosophical perspective from which they are viewed. Wittgenstein's elucidation of basic certainty is effected from two points of view: 1) phenomenological: here, Wittgenstein is describing what it is like to be basically certain; to have an attitude of basic certainty - and the answer is that it is like a way of acting or know-how or reflex action (like grabbing a towel from the towel rack without thinking). Here, 'I have a body' is the expression of a nonpropositional attitude; a way of acting in the certainty of having a body, acting embodied; 2) categorial: Wittgenstein is here describing the nature, place or status of basic beliefs; how they fit in our doxastic categories - and, from this point of view, they are seen to have the status of grammatical rules. 'I have a body' is the expression of one of the rules of grammar

\footnotetext{
${ }^{7}$ When asleep or unconscious, this belief remains a disposition, but becomes occurrent in any normal use she makes of her body - e.g., in her eating, running, her not attempting to walk through walls as if she were a disembodied ghost.

${ }^{8}$ A version of this question is posed by Genia Schoenbaumsfeld in this issue. My reply here applies to that version as well.
} 
which govern our making sense. These two descriptions seem incompatible but are not; they are complementary in elucidating both the phenomenological nature and philosophical status of our basic certainties.

\section{An ineffable certainty}

Indeed, the enacted nature of our hinges is such that Wittgenstein claims they are not even sayable - that is, uttering a hinge, qua hinge, in the flow of ordinary discourse is to speak nonsense; it is to utter a rule where no reminder of the rule is needed. If I were to say to the cloakroom attendant as I hand him my token: 'This is a token', he would look at me perplexed. Why am I saying this? 'The background is lacking for [this] to be information' (OC 461); the information the attendant requires in order to retrieve my coat is what the number on the token is. That this is a token is the ineffable hinge upon which his looking for the number on the token - and then looking for my coat - revolves. Our shared certainty that 'this is a token' can only show itself in our normal transaction with the token; it cannot qua certainty be meaningfully said. Articulating a hinge in the language game does not result in a display of certainty, but in a display of nonsense. It is perceived as queer; incomprehensible; a joke; a sign of madness (OC 553; 347; 463; 467). To utter a basic certainty within the language-game invariably arrests the game. Conversely, think of the fluidity of the game poised on its invisible hinges: I hand the attendant my token, he glances at the number on it and fetches my coat. Our foundational certainty is operative only in action, not in words 9 .

Of course, Moore and Wittgenstein do articulate some of our certainties, but they do so in a heuristic context ${ }^{10}$ : their articulations, we might say, are cases of 'mention' not 'use', and are not, therefore, subject to the nonsensicality to which they are subject when uttered in nonheuristic discourse ${ }^{11}$. Hinge certainties can be uttered in the study without this arresting

\footnotetext{
${ }^{9}$ Of course, their being ineffable does not prevent our hinges from showing themselves in what we say, but here too, certainty is animal. My hinge certainty that 'I have a body' is much the same as a lion's instinctive certainty of having a body. In both cases, the certainty manifests itself in acting embodied; in my case, however, it can also manifest itself in what I say; in the verbal references I make to my body, as when I say 'I lost weight' or 'My back hurts': 'Doesn't "I know that that's a hand", in Moore's sense, mean the same, or more or less the same, as: I can make statements like "I have a pain in this hand" or "this hand is weaker than the other" or "I once broke this hand", and countless others, in language-games where a doubt as to the existence of this hand does not come in' (OC 371).

${ }^{10}$ This qualification is important, but is often missed by commentators who find my view of the ineffability of hinges objectionable (e.g., Schönbaumsfeld and Kusch in this issue). Hinges are meaningfully sayable in heuristic circumstances, where what is transmitted is grammar (that is - broadly speaking - an unquestionable framework of thought). Such heuristic circumstances include straightforward conceptual instruction or elucidation, but they may also be less obvious. To Kusch's objection that hinges are also sayable as proverbs or platitudes, or - in the case of religious certainties, 'repeated again and again' in prayers, I would reply that these are also heuristic circumstances: to say again and again 'Our Father who art in heaven' or 'the LORD is God. It is he who made us, and we are his' (Psalm 100) serves partly to proclaim to the uninitiated the basic tenets (the grammar) of the creed. Of course, there is also an expressive or emphatic or ritualistic element in such repetition which - in line with Wittgenstein's analysis of such 'utterances' - makes them more akin to behaviour than statement (see Moyal-Sharrock 2000).

${ }^{11}$ Or when overheard by someone unaware of the heuristic nature of the circumstances: 'I am sitting with a philosopher in the garden: he says again and again "I know that that's a tree", pointing to a tree that is near us. Someone else arrives and hears this, and I tell him: "This fellow isn't insane. We are only doing philosophy."' (OC 467)
} 
the philosophical language-game. This is not because they become dubitable propositions when scrutinized in the pondered atmosphere of philosophical reflection, but because in the study their nature and status are being elucidated, and so they are mentioned, not used.

Philosophical articulation of basic certainties is important in that it allows us to individuate and elucidate them, but it can also be misleading: it can give the impression that our basic beliefs are propositional, epistemic and intellectual. We should, however, remember that our basic certainty is animal through and through. We can verbalise it, but this neither makes it into a proposition nor into an occurrence of basic certainty. Our basic certainty manifests itself exclusively in action. It is a logic in action. Note, then, that Wittgenstein's innovation is not that certainty is a precondition to action - that is rather banal - but that certainty is action ${ }^{12}$. That is, a certainty whose status is grammatical or logical, and whose manifestation is enacted.

To say that hinges underpin knowledge is not to say that knowledge is all they underpin. As Wittgenstein writes: they 'form the foundation of all operating with thoughts (with language)' (OC 401; my emphasis), of our language games (OC 403) - which means that they are as much the basis of our false beliefs as of our justified true ones. Our basic certainties make up our world picture, which Wittgenstein refers to as a 'mythology' (OC 95), not in the sense that it is a mystifying picture, but in the sense that it is a picture which is not grounded in - that is, justified by, science (knowledge): 'I did not get my picture of the world by satisfying myself of its correctness; nor do I have it because I am satisfied of its correctness' (OC 94).

\section{A groundless - and yet rock solid - certainty}

Duncan Pritchard notes that this 'groundlessness' poses a problem in that it generates a limited form of scepticism ${ }^{13}$ - i.e. we can't know everything:

\footnotetext{
On [Wittgenstein's] view the regress of reasons comes to an end, but it does not come to end with further reasons of a special foundational sort as we were expecting. Instead, when we reach bedrock we discover only a rationally groundless 'animal' commitment (OC 359), a kind of 'primitive' trust (OC 475). For Wittgenstein, understanding that this is so is meant to be the antidote to radical scepticism, and yet it must surely be admitted that, superficially at least, it looks very much like a version of radical scepticism. (Forthcomingb, 5)
}

And because there cannot be a satisfactory rational way of terminating the regress of reasons, what Pritchard calls 'epistemic vertigo' obtains ${ }^{14}$ :

\footnotetext{
12 Even mathematical propositions should, according to Wittgenstein, be thought of as prompting or expressing acts or moves. Rules of mathematics are akin to orders or commands that impart technique (RFM VII 1, 40; V 13) - 'The mathematical proposition says to me: Proceed like this!' (RFM VII 73); it 'determines ... lays down a path for us' (RFM IV 8). Calculating, using mathematical rules, are mechanical activities; like making moves that one was trained to perform. Much as for the people in one of Wittgenstein's thought experiments, 'the centre of gravity' of our mathematics lies 'entirely in doing' (RFM IV 15). Indeed Wittgenstein often remarks on the dispensability of propositions in arithmetic, stressing the similarity of calculating to gestures, and of the teaching of arithmetic to a training (RFM III 4).

13 'After all, to be told that all rational support takes place relative to a backdrop of ungroundable certainties does sound an awful lot like scepticism' (Pritchard, Forthcomingb, 5).
} 
Prior to engaging with the radical sceptical paradox we implicitly took it as granted that there were ultimate grounds for our belief and that they were secure, but now that we have engaged with this problem we have to live with the recognition of the ultimate groundlessness of our believing. (ibid. 8)

Hence the vertigo.

I agree with Pritchard that Wittgenstein's groundless certainty is bound to cause vertigo in some, but I would stress that such vertigo is due to the idée fixe that justification is the only acceptable standard (in spite of Gettier showing that it too can be unreliable). And so I cannot agree with Pritchard that 'epistemic vertigo as a response to even an undercutting antisceptical strategy is an integral part of the human epistemic condition' $(2013,34)$. If vertigo is experienced, it is only by the epistemologist who assumes knowledge - justified true belief - to be the highest possible form of certainty. The groundlessness that undercuts the sceptic may cause vertigo to those who overvalue knowledge, but this makes epistemic vertigo a psychological problem, not an inherent human condition due to the groundlessness of our beliefs.

For, groundlessness as depicted by Wittgenstein is not an epistemic lack, failing or limitation - not something that would allow the sceptic to triumph - but, on the contrary, descriptive of something so robust, so anchored, so unquestionable that it is not built on the back of justification or grounds ${ }^{15}$. Groundlessness here does not denote precariousness, but characterizes the rock solidity that makes our spades turn and allows us to 'stand fast' (OC 152) (not reel over); the certainty on which all our knowledge is logically hinged.

Moreover, though groundlessness means absence of justification or reasoning, it does not mean detachment from reality: our hinges are conditioned by how the world is, by 'very general facts of nature'; they are rooted, albeit not ratiocinatively, in our human form of life and in the various forms of human life ${ }^{16}$.

14 (2012b, 4; 6-7) Pritchard fleshes out what he means by 'epistemic vertigo' as follows: 'In conducting a philosophical inquiry into the nature of our epistemic commitments we effectively 'ascend' to an investigation which is unfettered by practical concerns, but what we discover as a result of this investigation, if Wittgenstein is right, is that our practices of epistemic evaluation are essentially local and thus that our believing is ultimately groundless. ... just as someone atop a high tower can fully recognise that he is not in danger, and yet fear the height nonetheless, so someone who undertakes the kind of philosophical investigation that we are conceiving of can intellectually recognise that there is no actual epistemic danger (in the sense that the kind of improvement in their epistemic situation that was initially sought after is simply unavailable), while nonetheless feeling the epistemic vertigo' $(2013,34)$.

${ }^{15}$ Pace Genia Schönbaumsfeld (2012ms \& in this issue), the concept of groundlessness is needed in that it helpfully underlines the absence of reasoning or justification or grounds; its use by Wittgenstein needn't imply that groundlessness is an absence where there ought to be a presence (i.e. grounds); it is simply a helpful contrast to cases of assurance which are reliant on grounds (such as knowledge).

16 Just as Wittgenstein acknowledges the impact of reality on our grammar (see Moyal-Sharrock 2013a \& Forthcomingb), he acknowledges the impact of experience on our hinge certainties, but insists that in neither case is this impact due to reasoning. To distinguish this nonratiocinated (unreasoned) rootedness in reality from a ratiocinated or justified rootedness, Wittgenstein opposes 'cause' and 'reason': 'What reason have I, now, when I cannot see my toes, to assume that I have five toes on each foot? Is it right to say that my reason is that previous experience has always taught me so? Am I more certain of previous experience than that I have ten toes? That previous experience may very well be the cause of my present certitude, but is it its ground? (OC 429); 'This game proves its worth. That may be the cause of its being played, but it is not the ground' (OC 474). So that, contra Kusch (in this issue), our lifelong experience of ourselves as handed (cf. Wright 2004a, 36) [or 'toed', in reference to the passage above] may be the 'cause' of our certainty; but it is not its 'ground'. It may help here to distinguish between 'experiential' (embedded in experience) and 'empirical' (inferred from experience). 
The point about knowledge that Wittgenstein is making in On Certainty is that it isn't as widespread as we think: most of what epistemologists think we know - i.e. our basic beliefs - we do not know. So that Wittgenstein would agree with the sceptic that our assurance about the existence of the external world or the world being more than five minutes old, or our having a body, or a hand, or a toothache, is not something we know: 'For when Moore says "I know that that's ..." I want to reply "you don't know anything!"' (OC 407). Another Wittgensteinian reminder that may be said to add grist to the sceptic's mill is that we can always be wrong in our claims to know: 'One always forgets the expression "I thought I knew"' (OC 12). Gettier has given this reminder more potency by showing that even justified true belief doesn't always amount to knowledge.

At most, then, the sceptic may be right to affirm we can never be sure of knowing, but this does nothing to unsettle our hinges. Without these hinges, there is no asking questions or raising doubts - sceptical or otherwise; and this - not any demonstration of justified true belief - is what defeats global scepticism. Granted, knowledge is not always where we think it is, but much of the time it is; and certainty, well, there's no doubting it - and there's no doing or thinking without it - not even sceptical thinking.

For Wittgenstein, hinges are the ungrounded ground; the unfounded foundation of thought and action; with them, he says, we arrive at the rock bottom of our convictions (OC 248). And yet in spite of the abundance of foundational images and remarks characterising hinge certainty, most commentators deny its foundational character because hinges lack some of the features of foundational beliefs on the traditional picture'17. Yet as previously mentioned, hinge certainties have their place in a foundationalist structure as the grammatical underpinnings of our beliefs. This, it seems to me, is a modification of foundationalism, not the absence of it. That hinges lack some of the features of foundational beliefs as traditionally conceived should not prevent them from being foundational. In fact it is precisely their differing from the rest of our beliefs (in being nonpropositional and nonepistemic) that makes for the success of Wittgenstein's foundationalism. It is the realization that what we have traditionally taken to be propositional beliefs (rationally posited or arrived at) are in fact ungrounded or logical ways of acting that allows Wittgenstein to put a stop to the regress of justification. Insisting that propositions lie at the foundation may satisfy epistemologists, but it will not solve the problem of regress.

\section{Entitlement}

Crispin Wright refuses to admit the animal in epistemology. And so, although forced to countenance the groundlessness of 'hinge propositions', he simultaneously upholds (what he

\footnotetext{
${ }^{17}$ According to Williams, there are four characteristics of traditional foundations: universality, specifiability, independence and adequacy $(2005,51,57)$. As I have argued elsewhere: some hinges are universal - hence the universality condition is met; there are features that constitute the criteria which allow us to distinguish basic beliefs from other beliefs - hence the specifiability condition is met; thirdly, the grammatical or logical nature of hinges gives them their independence or autonomy (remember, that for Wittgenstein grammar is autonomous) as well as, fourthly: their logical adequacy. I am not sure meeting these conditions is essential to gaining entry to the foundationalist club, but I believe hinge certainties can be shown to meet Williams' conditions, and can be seen to amount to a theory of knowledge.
} 
takes to be) their rational nature. He seeks to do this by thinning down the type of rationality at work here. Wright argues that absence of justification does not imply absence of a warrant to believe; there is 'a type of rational warrant which one does not have to do any specific evidential work to earn'; this nonevidential or 'unearned warrant' or 'warrant for nothing', he also calls 'entitlement' (2004b, 174).

I borrow Pritchard's summary of the entitlement or epistemic internalist reading of hinges:

... one can have knowledge of hinge propositions even while lacking adequate rational support for believing these propositions to be true. ... This special kind of rational support is known as entitlement. In essence, the idea is that where we are obliged, on pain of cognitive paralysis, to be committed to certain propositions which we have no reason for thinking are true, then, so long as there is no reason available for thinking those propositions to be false, one has a default rational basis - an entitlement - for these commitments (2012a, 263-4).

We immediately wonder here how such an entitlement can still be referred to as 'knowledge' without the standard definition of knowledge being flouted. This is probably why - though without ceasing to refer to it as epistemic and rational - Wright call it an 'entitlement to trust'; where trust, though not as robust as belief proper when it comes to rationality, 'is not per se irrational': 'Entitlement is rational trust' (2004b, 194). How is it rational? The prevailing answer seems to be: that our forming basic beliefs 'falls short of the ideals of our reason' does not prevent it from being rational; we accept strategic entitlement in order to avoid cognitive paralysis (2004a, 50). It becomes clear that the 'rational' in Wright's 'rational trust' does not mean 'reasoned'; it is not a properly cognitive or epistemic process - and certainly not a logical feature - but a merely pragmatic attitude. And yes, of course, there are pragmatic reasons that may influence or shape our epistemic processes, but they are not properly epistemic ${ }^{18}$. The 'rational' in 'rational trust' is a pragmatic notion in epistemic dress; Wright uses it ambiguously and his argument trades on this ambiguity ${ }^{19}$.

Wright later attempts to inject some epistemic juice into his 'entitlement' by suggesting that 'basic judgments' are made 'for no reason that can be captured via the modus

\footnotetext{
${ }^{18}$ Wright talks of a 'Welfare State Epistemology' with regard to some propositions: 'This is not to say that the required "prior reason" must be deliberately thought through or entertained by the beneficiary. The best versions of the notion of rational entitlement will belong with a kind of Welfare State epistemology: entitlements will be benefits by which one may live well, doxastically speaking, without having to do any epistemic work by way of qualification for them' (2007b note 6). Wright's is a pragmatic, not an epistemic, response to scepticism; as Pritchard also notes, his view faces the serious problem of explaining in virtue of what the epistemic support for our hinge beliefs consists, given that it is not an epistemic support that comes through being appropriately grounded (2011b, 545).

${ }^{19}$ That is, while conceding that there is no rational basis - in the sense of no reasoning or justification - for our holding on to certain propositions, Wright claims that this does not prevent them from being rationally held here, rational in the sense of a pragmatic avoidance of cognitive paralysis. Pritchard also sees Wright's argument as trading on the 'ambiguity in the very notion of a rational trust', though he sees the ambiguity slightly differently. By this expression, he takes Wright as meaning that one's trusting what one is told by this informant is rational to the extent that there is some reason available, however slender, for treating what she says as true. Depending on the degree of rational support in play, rational trusting of this sort may well exclude agnosticism about the truth of the target propositions. But 'rational trusting' as it is used by Wright clearly does not mean this at all, since it remains that for him one's trust is supposed to be compatible with one being aware that one possesses no rational basis whatsoever for regarding the target propositions as true. Rather, the rational basis one has for engaging in this trust is entirely disconnected from being a rational basis for regarding the target propositions as true' (Forthcominga, 9-10).
} 
ponens model' rather than 'made for no reason at all' (2007a, 499). However, I have not found any account of his that varies from his seeking to dilute Wittgenstein's groundless certainty into a certainty with some grounds, of a pragmatic kind.

To say that our basic beliefs are 'animal' is to say that they are arational and ungrounded, and that is non-negotiable: they cannot be both grounded and ungrounded; both arational and rationally warranted. Wittgenstein explicitly denies that absence of justification as regards basic beliefs might be due to practical considerations; i.e.: '... it isn't that the situation is like this: We just can't investigate everything, and for that reason we are forced to rest content with assumption'20 (OC 343). Rather: 'it belongs to the logic of our scientific investigations that certain things are in deed not doubted' (OC 342).

If, as Pritchard helpfully explains, the basic thinking behind the entitlement strategy is that it is meant to constitute a more realistic conception of the nature of rational support (Forthcominga, 5), I want to ask why such a conception needs, at all costs, to hold on to the concept of basic knowledge or to our entitlement being rational. Rather than thin down our concept of knowledge which, in spite of some technical problems à la Guettier, has certainly proved its value since Plato - why not simply admit that basic beliefs are not known at all which, as Wittgenstein shows - does not make them any less operative and preventive of cognitive paralysis.

I have been claiming that Wittgenstein's analysis of our basic certainties in $O n$ Certainty show them to be indubitable, nonepistemic, nonpropositional, grammatical and enacted. I would like to come back to the nonpropositional feature, as it has caused resistance in my closest fellow-readers of On Certainty.

\section{Objections to the nonpropositional reading}

By showing that basic beliefs are nonpropositional, Wittgenstein puts a stop to the regress that has plagued epistemology: we no longer need to posit untenable self-justifying propositions at the basis of knowledge. And yet, Annalisa Coliva (2010) and Duncan Pritchard - although they, unlike Williams and Wright, take hinges to be nonepistemic - find my nonpropositional reading of hinges objectionable. Again, I suspect this might reflect a general resistance on the part of epistemologists to admit the 'animal' into their midst. As I have elsewhere addressed Coliva's objection ${ }^{21}$, I will now briefly address only Pritchard's account of hinge propositions as 'simultaneously unknowable and yet the possible subject of a propositional attitude' (Pritchard 2013, 31).

Pritchard finds problematic the nonpropositional reading of hinges, particularly because, on his view, it struggles with the Closure Principle, which goes like this: 'If I know that $\mathrm{p}$, and I competently deduce $\mathrm{q}$ from $\mathrm{p}$, then I know that q'. So, for example: If I know that Napoleon won the battle of Austerlitz in 1805, and I competently deduce on this basis that the universe did not come into existence five minutes ago, then I also know the entailed proposition; i.e. that the universe did not come into existence five minutes ago. I'm not quite sure which one of the versions of the Closure Principle (Closure K, Closure KR), including

\footnotetext{
${ }^{20} \mathrm{He}$ is unequivocal in declaring that 'the end [our basic belief] is not an ungrounded presupposition' (OC 110); and he does not want 'to regard this certainty ... as something akin to hastiness or superficiality (OC 358).

${ }^{21}$ See Moyal-Sharrock (2013b).
} 
the Transmission Principle, would best render the problem here, but I think it's enough for our purposes if we understand Pritchard's objection to be that the nonpropositionality of hinges would preclude their transmitting across competent deductions, thereby denying any version of the Closure Principle. This is a general concern in that, by insisting that hinge propositions - as he calls them - cannot be known, proponents of the nonpropositional reading are bound to either reject the highly intuitive Closure Principle or else grant that an awful lot of what we take ourselves to know is in fact unknown (2012a, 268-69). But a more precise concern is that, if this principle is rejected, it becomes mysterious how we are apparently able to use competent deductions to extend our rationally-grounded knowledge (ibid. 260). Here is Pritchard's summary of the problem:

The key difficulty facing the non-propositional reading is to see how it ultimately amounts to anything more than simply embracing a mystery. ... how ... are we to make sense of the apparent ease with which we make the relevant inferences?

For while it might be plausible to contend that prior to undertaking philosophical reflection we do not form any propositional attitude at all to hinge propositions, it is hard to see how, subsequent to engaging in the relevant philosophical reflection, we can avoid adopting a positive propositional attitude to these propositions. How could one recognise that a certain historical event (e.g., the battle of Austerlitz) took place at such-and-such a date, and that this entails that the universe has been around for more than $5 \mathrm{~min}$, and yet not adopt a positive propositional attitude ... to the entailed proposition? (ibid. 266)

My answer to the question of how we are to make sense of the apparent ease with which we make the relevant inferences is simply: we don't make such inferences at all. The belief that a certain historical event took place at such and such a date does not entail that the universe has been around for more than five minutes but is rather underpinned by it. We could not believe that the battle of Austerlitz took place in whatever year, were we not hinged on the certainty that the universe has been around for more than five minutes.

The putative 'entailed proposition' is not a proposition at all but a mere formulation of the certainty on which recognizing that the battle of Austerlitz took place in 1805 is hinged. And so, although it may look like an entailment, the 'entailment' is only apparent: the socalled 'entailed proposition' invisibly underpins the Austerlitz proposition and does not result from it. The so-called entailment would at best be circular - that is, an entailment hinged on itself via the Austerlitz proposition. Perhaps, the reason Pritchard thinks we make such inferences is that he seems to adopt the Humean stance, which turns hinges into propositions as soon as they are the object of philosophical scrutiny; as he writes: 'it is hard to see how, subsequent to engaging in the relevant philosophical reflection, we can avoid adopting a positive propositional attitude to these propositions'.

On Pritchard's view, rejecting the closure principle puts the nonpropositional reading in a quandary 'given that we do seem very able to formulate the propositions expressed in hinge commitments, and recognise their logical relationships to other propositions which we rationally believe and know' (2012a, 269). But, as we saw earlier, the fact that we are able to formulate our hinge commitments should not lure us into thinking that this makes them into propositions - for, propositionality demands truth evaluability, and hinges are not truth- 
evaluable $^{22}$. As to the logical relationship between hinges and propositions which we rationally believe and know, we do recognise it, as that between rules and propositions. And it is precisely their being rules that makes hinges nonpropositional.

So I don't see that the non-propositional reading faces the mystery of accounting for the apparent propositional attitude generated by competent deductions, for there is, in the case of hinges, no such propositional attitude ${ }^{23}$. The nonpropositional reading cannot be taxed with the costly consequence of rejecting the closure principle for it doesn't affect the closure principle at all. The closure principle concerns knowledge claims, not hinges. And if hinges not being susceptible to the closure principle means that 'an awful lot of what we take ourselves to know is in fact unknown', why this is precisely what Wittgenstein is saying in On Certainty: we don't know our basic beliefs, as we - and Moore in particular - thought we did.

The insistance on the nonpropositionality of basic certainty is not a mere technical point: it is one with their being 'animal'. If for Crispin Wright: 'There is no animal in epistemology!', for Wittgenstein: 'It is there, like our life' (OC 559). Wittgenstein's conception of hinge certainty enables us to rid ourselves of the misguided assumption that propositions are indispensable to our grasp of the world. It seems to me, then, that to maintain that hinge certainties are propositions is to revert back to that assumption, and with it to the traditional view of basic beliefs that would deprive us of Wittgenstein's solution to the problem of their regress.

If all Wittgenstein were doing in On Certainty was to claim that our basic beliefs are true propositions, why bother? He would be merely repeating what philosophers before him have been saying for centuries, all the while deploring an unsolvable infinite regress. Why not rather appreciate that Wittgenstein stopped the regress? And that that required nonpropositionality.

\section{Conclusion: Wittgenstein's enactivism meets epistemology}

Far from devaluing knowing, Wittgenstein reaffirms its role in our epistemic practices, but he also makes two major adjustments: he removes it from its position as the most fundamental of our assurances, and points out the erroneous conflation of knowing and claiming to know which results from our impression that the latter, when done in earnest and in the appropriate circumstances, guarantees knowledge (OC 21). In the foundational position traditionally held by knowledge, Wittgenstein places certainty. A certainty which is both animal and logical. By

\footnotetext{
22 Though, as discussed above, the Doppelgänger of hinges may be.

${ }^{23}$ Inasmuch as our hinge commitments cannot be the result of a rational process and are in their nature unresponsive to rational considerations, Pritchard thinks they cannot be beliefs, and thereby possibly amount to knowledge. Yet regarding our hinge commitments as visceral in the way Wittgenstein demands, while no doubt inconsistent with regarding them as akin to normal beliefs, doesn't prevent them, Pritchard suggests, from being expressed via other propositional attitudes. And so he proposes 'the non-belief reading': 'the nonbelief reading can grant that someone who undertakes the relevant competent deductions could be described as having a propositional attitude towards the entailed hinge commitment, without thereby having to face the question of why this propositional attitude doesn't amount to knowledge' (Forthcomingb, 13-15). Pritchard would need to say more on what this nonbelief propositional attitude would be, but this wouldn't detract from the fact that hinges are not propositional at all, nor do they need to be to safeguard a principle they have nothing to do with. For my view of Pritchard's notion of 'überhinge', see Moyal-Sharrock (Forthcominga).
} 
this he means that its indubitability, though essential to our making sense, is not the result of thought and can only manifest itself as a way of acting.

The sceptic may then claim partial victory in Wittgenstein's affirmation that we don't know that external objects exist or that we are not brains in vats; but the more radical victory is on the side of certainty: 'That is to say, it belongs to the logic of our scientific investigations that certain things are in deed not doubted' (OC 342). With this, Wittgenstein recognises that the real certainty that underpins our investigations - in fact, all that we say and do, our language-games generally - is an enacted, not a propositional certainty:

But is it wrong to say: 'A child that has mastered a language-game must know certain things'?

If instead of that one said 'must be able to do certain things', that would be a pleonasm, yet this is just what I want to counter the first sentence with. (OC 534)

And with this, Wittgenstein's enactivism impacts epistemology.

I have attempted in this paper to elucidate Wittgenstein's account of basic certainty by fleshing out the features that define it. Other commentators have, in their own accounts, preferred to leave out some of these features: hinge certainty has been deemed epistemic but not justified; nonepistemic but not animal; unreasoned but not arational; arational but propositional; nonpropositional but not completely; and so on. These various compromises, I have suggested, reflect two main difficulties: it is difficult for epistemologists to give up the idea that knowledge is our fundamental form of conviction; once this psychological barrier is crossed, the next real barrier is nonpropositionality. Propositionality is difficult for the epistemologist to give up because its absence makes room for the 'animal' in epistemology; with nonpropositionality, we seem to give up our grip on the rational. But what On Certainty shows us is that our distrust of the arational (the animal) and our reliance on propositions are excessive: 'I want to regard man here as an animal; as a primitive being to which one grants instinct but not ratiocination. As a creature in a primitive state.' (OC 475). It is only by realising that putting ways of acting into sentences is only a heuristic tool designed to better understand the animal, that we can take, as Wittgenstein did, the uncompromisingly revolutionary step to stop the regress of justification.

'If - says Pritchard - [Wittgenstein's] new conception of the structure of reasons could be made defensible, then it would clearly have far-reaching ramifications for epistemology. The difficulty, however, is knowing how to turn Wittgenstein's sketchy remarks on this topic into a concrete proposal' (Forthcomingb, 5). I hope to have shown how Wittgenstein's remarks are a defensible concrete proposal, and that they therefore have far-reaching ramifications for epistemology. 
References

Coliva, A. (2010) Moore and Wittgenstein: Scepticism, Certainty, and Common Sense. Basingstoke, UK: Palgrave Macmillan.

Malcolm, N. (1958) Ludwig Wittgenstein: A Memoir. London: Oxford University Press.

Moyal-Sharrock, D.

(2000) 'Words as Deeds': Wittgenstein's 'Spontaneous Utterances' and the Dissolution of the Explanatory Gap Philosophical Psychology 13:3 (September 2000), 355-372.

(2007) Understanding Wittgenstein's On Certainty. Basingstoke, UK: Palgrave Macmillan.

(2013a) 'Realism, but not empiricism: Wittgenstein versus Searle' in A Wittgensteinian Perspective on the Use of Conceptual Analysis in Psychology, eds Timothy P. Racine and Kathleen L. Slaney. Basingstoke, UK: Palgrave Macmillan, 2013, 153-71

(2013b) 'On Coliva's Judgmental Hinges' Philosophia (March 2013) 41:1, 13-25.

(Forthcominga) 'Knowledge and Certainty' in Blackwell Companion to Wittgenstein, (eds.) H.-J. Glock \& J. Hyman. Oxford: Blackwell.

(Forthcomingb) 'Wittgenstein: No Linguistic Idealist' in Wittgenstein and the Creativity of Language, eds S. Greve and J. Mácha. Basingstoke, UK: Palgrave Macmillan, 2015.

Pritchard, D.

(2011a) 'Epistemic Relativism, Epistemic Incommensurability and Wittgensteinian Epistemology' in S. Hales (Ed.) The Blackwell Companion to Relativism. Oxford: WileyBlackwell, 266-85.

(2011b) 'Wittgenstein on Scepticism' in The Oxford Handbook of Wittgenstein, ed. M. McGinn. Oxford: Oxford University Press, 2011, 523-49.

(2012a) 'Wittgenstein and the groundlessness of our believing' Synthese 189: 255-72.

(2012b) 'Wittgensteinian Pyrrhonism' in Pyrrhonism in Ancient, Modern, and Contemporary Philosophy, Vol. 70 of The New Synthese Historical Library (2012), 193-202.

(2013) (with C. Boult) 'Wittgensteinian Anti-Scepticism and Epistemic Vertigo', Philosophia 41: 27-35.

(Forthcoming a) 'Entitlement and the Groundlessness of Our Believing' in Scepticism and Perceptual Justification, (eds.) D. Dodd \& E. Zardini. Oxford University Press.

(Forthcoming b) 'Wittgenstein on hinge commitments and radical scepticism in On Certainty' in Blackwell Companion to Wittgenstein, (eds) H.-J. Glock \& J. Hyman. Oxford: Blackwell.

Schönbaumsfeld, G. (2012 ms) 'Meaning and Conversational Impropriety in Sceptical Contexts'.

Von Wright, G.H. (1982) Wittgenstein. Oxford: Basil Blackwell.

Williams, M.

(1991) Unnatural Doubts: Epistemological Realism \& the Basis of Scepticism. Oxford:

Blackwell.

(2001) Problems of Knowledge: A Critical Introduction to Epistemology Oxford: Oxford University Press.

(2005) 'Why Wittgenstein isn't a Foundationalist' in Moyal-Sharrock, D. \& William H. Brenner, eds (2005/2007) Readings of Wittgenstein's On Certainty. Basingstoke, UK: Palgrave-Macmillan), 47-58. 
(2007) 'Why (Wittgensteinian) Contextualism Is Not Relativism', Episteme 4:1, 93-114.

Wright, C.

(2004a) 'Wittgensteinian Certainties' in D. McManus (ed.) Wittgenstein and Scepticism. London: Routledge, 22-55.

(2004b) 'Warrant for nothing (and foundations for free)?' Proceedings of the Aristotelian Society, 78 (suppl. vol.), 167-212.

(2007a) 'Rule-following without Reasons: Wittgenstein's Quietism and the Constitutive Question' in J. Preston (ed.) Wittgenstein and Reason, Ratio 20: 4, 481-502.

(2007b) 'The Perils of Dogmatism' in S. Nuccetelli \& G. Seay (eds.) in Themes from G.E. Moore: New Essays in Epistemology and Ethics. Oxford: Oxford University Press, 25-48. 